\title{
Assimilation Techniques and Technological Methods, Implemented in the Teaching and Learning Process
}

\author{
MSc. Senada Bushati (Hoxha) ${ }^{1}$ \\ Prof. Dr llia Ninka² \\ MSc. Fatjona Bushi ${ }^{3}$ \\ ${ }^{1}$ Head of Computer Science Department, Faculty of Information Technology, \\ "Aleksander Moisiu" University of Durres \\ ${ }^{2}$ Head of Informatic Department, Faculty of Natural Sciences, Tirana Universitety \\ ${ }^{3}$ Lecturer of Computer Science Department, Faculty of Information Technology, \\ "Aleksander Moisiu" University of Durres \\ bushatin@yahoo.com
}

\section{Doi:10.5901/mjss.2013.v4n3p763}

\section{Abstract}

The principal progress made over the last years in ICT and its usage on the education system can be attributed to advances in three areas: prediction, classification and modeling methods. We propose that education should also be extended into the domain of data miting methods and ICT assimilation.Albanian environment is increasingly being assimilated more new techniques and methods from western countries, and is applied in various fields of life. More and more platforms are being used to help the educational process. Recently new technologies and methods offer new alternatives and new possibilities to learning management systems. In this paper is presented through a questionnaire survey, the Albanian education environment. The aim is to show how these techniques are used and what the requirements for the future are. Also we want to examine the potential uses of distance learning platforms for maintaining and sustaining the educational environment. It includes a brief examination of distance education in general, some statistics based on the answers given on the questionnaire and an analysis of the potential outcomes and the impact of these practices. This study examines the implementation of distance learning through an analysis of how the Albanian students are trying to use these technologies \& methods, and with what impact of performance.

Keywords: ICT; distance learning; learning management systems; technological tools; educational data mining; learning and teaching methods;

\section{Introduction}

Computer and Internet are seen as one of the needed technologies in teaching. Internet is the technology that has revolutionized teaching in every part of the world. Through the internet was achieved that teacher is not the only point of reference, but is coordinator of new entries in the student's educational culture. Not long ago these were considered innovative technology, they are now indispensable due to technological orientations have included the teaching process. Today the school is in terms of competition for forming and reforming people. Once the school was the only institution of learning, it isn't so today. We say this not in the figurative sense, but should not be surprised if the student knows something more than the teacher. Like our thought schools will maintain the role of setting standards in knowledge. Knowing the students step by step with the degree of fulfilling their objectives, represents a powerful incentive mechanism, this should be considered a priority by the teachers. Young people today are deeply attached to the world of the Internet.

According to the research, school with its conservative character, can not act like a not known circumstances of today's learning and self-learning. Also merit to changes in the national curriculum, they have the opportunity to learn computer use, but also to use the basis material of the informatics laboratories that are in schools and universities. The fact that many students are in classes associated with technological tools, shall become the most enjoyable time and ease process of learning is an objective that we should always have in mind. Because it inhances the student activity in the learning process, so will be increased the performance of the education system. 
Curricula based on ICT is changing rapidly, where all ICT subject teachers are trained and other subjects teachers are trained to use ICT in the relevant syllabus, exams are being digital, are built electronic systems of national registries pupils, students, teachers and lecturers, each student will have a national registration number. Administration and management of the education system is being modernized at all its levels.

This article is a summary and an overview of research conducted in connection with the use of technological tools and platforms, in the Albanian education system. Paper is part of my PhD studies; we want to show the impact and high performance, which could lead the use of these tools. The term 'tools' includes different techniques and methods in technology, which have found wide application in various aspects of our lives, such as business, scientific research, experiments, statistics etc. Through this study we are seeking to show that these methods and techniques can be implemented even in the field of education as a tool that will bring innovation in Albanian educational environment.

\section{Research methodology}

The rapid changes over the last years present new challenges and put new demands on the Albanian education system. The process of teaching is adapted to the different characteristics of the students by using diverse methods of teaching. We must consider that there are different ability levels, learning styles, personality characteristics and knowledge backgrounds. The goal of education is viewed as the transmission of knowledge by the teachers to the students, based on traditional process learning.

Nowadays the goal of education system is viewed as facilitating students' autonomous learning and self expression. [3] It is a process in close relationship with the technological tools. The adaptation to the personal characteristics of students, through a non uniform teaching \& learning process is expected to be more effective, because students are independent, active, self-researchers etc. This process becomes simple if we have a combination of technology and e-learning platforms with teaching and learning process. These techniques and methods are proven in many educational and academic environments in the world, so why not integrate.

To achieve this purpose, we refer to the general structure of the educational process for treating its key points; we are able to determine the proper technique and technological approach, which help in this process. The following shows some elements that help us to this end:

Introduce the Skills - knowledge system, involvement of all students, Relation to real life and determine the goals

Modeling the Skills - To determine who will be the main character in the learning process. Referring to the goal that we have, we will have some characters, because their knowledge already are being processed by cooperative learning.

Implementation of technology - Students have the opportunity to practice their new skills under the teacher's supervision, implementing distance learning platforms. This is a good opportunity for cooperative learning, where students can work, stand alone with their idea and also can collaborate with each other.

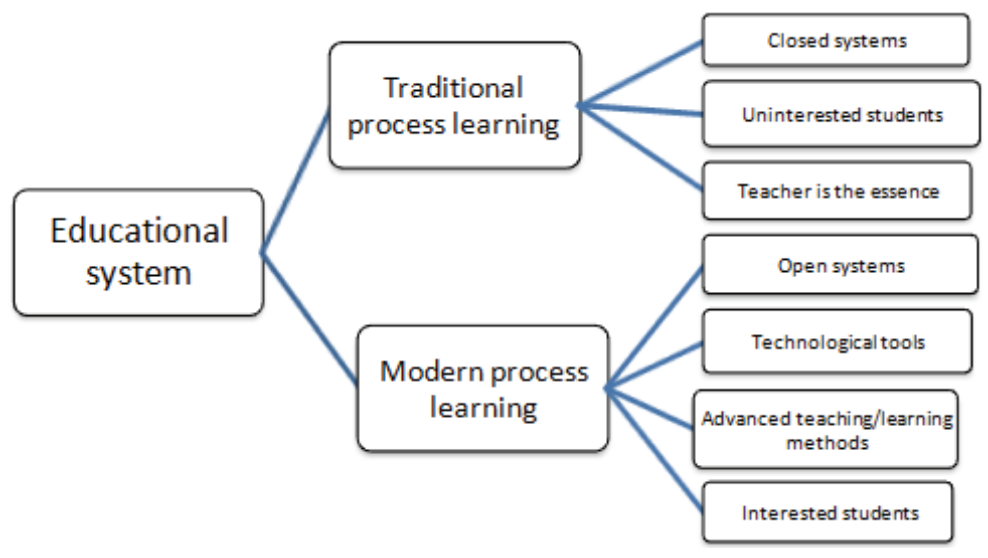

Figure 1. Educational Process

As stated above, this article is part of our doctoral studies. It is a result of work came after two-years of collection and processing data. The method that is used is the questionnaire, because our country still does not have a genuine use of 
e-learning platforms, data mining techniques and semantic web on their teaching.

Our dissertation proceeds in four parts. First, we study the system education in general. We then explore in very general terms traditional process education in Albania. Later we discuss the uses of this technology. Finally, we analyze the potential outcomes and consequences of these practices.

The questionnaire consists of 60 questions, which aim to show the relationship of technological tools with teaching process and the individ (learner / student or teacher / Lecturer). The first part of it has to do with a set of questions that give information about the interviewees, in order to be accurate with the result that would give. The second part deals with questions which show the relationship of the educational system with various technological tools that can be used in the teaching and learning process, questions which aim to show the technological forms which are present in the Albanian education system, and which is the way of using them. In the third part the goal is to show which the current Albanian teaching process is and specification of changes occurred especially in the last 5 -years. The last part deals with questions that show the impact that may have used of technological tools and techniques and LMS platforms in the educational system.

The study was conducted in a sample environment (50 people) who is interviewed and each of responded on an individual manner to the questions, based on his personal experience and knowledge. This study is thought to extend over 500 people Also the questionnaire was conducted in two areas: pupil / student and teacher / lecturer. This division gives a more detailed overview of the responses, creating an opinion on the thoughts of students, who are independent and indifferent and opinions of teachers and lecturers, who are responsible in what they think and express. So we have a crude opinion of the comparisons based on desire and voice of experience. Machine learning algorithms are usable techniques in educational environment.

We have used RapidMiner environment for data processing and calculation of results. Rapid Miner is a platform that has many integrated algorithms which are helpful to us for our study.

RapidMiner (formerly Yale) is an environment for machine learning and data mining processes. A modular operator concept allows the design of complex nested operator chains for a huge number of learning problems. Today, RapidMiner is the world-wide leading open-source data mining solution and is widely used by researchers and companies. RapidMiner introduces new concepts of transparent data handling and process modelling which eases process configuration for end users. [4]

Data mining uses a combination of an explicit knowledge base, sophisticated analytical skills and domain knowledge to uncover hidden trends and patterns. These trends and patterns form the basis of predictive models that enable analysts to produce new observations from existing data.[5]

DM techniques and methods can be used in every aspect of our lives, as business, bio-informatics, medicine, games, engineering etc. Now are well adapted to the teaching environment. There are also created new techniques that are used entirely for the purpose of educational environment. Regarding the high schools and middle high schools, the use of e-learning platforms or LMS affects on improving the performance of the learning process. We are able to monitor the performance of each student, teacher, etc., and can extract data, which can be used by DM techniques to achieve certain goals.

Regarding the passage Maturity - University of students, DM techniques can provide efficient data that will be choices towards their future. The information analyzed by DM methods based on the experiences of previous years serves as decision-making information. With regard universities as institutions, DM techniques can help to improve the educational system, raising a personalized education system, reducing the cost of educational processes, expansion of a university. Use DM for monitoring and predicting the transfer of student groups offers significant benefits to decisionmakers, advisors and students. [6]

\section{Findings and discussion}

From this study we came to several conclusions. It is made a lot of work in terms of preparation of the material, but on the other hand also a preparation needed by teachers and students in the knowledge, and the practical use of technology. Fear of innovation in many cases step, new experiences are often viewed as suspicious by senior teachers who already have a background on the basis of a certain ideology and methodology. They are critical of this idea, introducing technology in teaching. During the various questions that we made through the questionnaire, most of us joined the same idea in terms of technologies, which are very necessary, to allow a better teaching which is not based on the teacher, the teacher now, is just a coordinator interactions. 


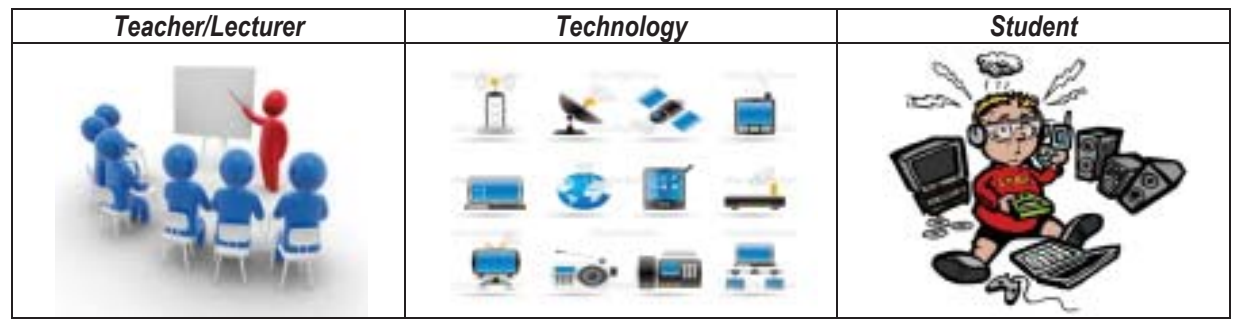

Figure 2. Learning Process over the years

After explaining the way that we have organized the study and the method that we used, the moment came to give some of the results achieved. Below I show some of the questions of the questionnaire and the response rates based on data: Question to the students, is: What are the reasons of PC and Internet usage in your life? Based on the responses, we have achieved the following results:

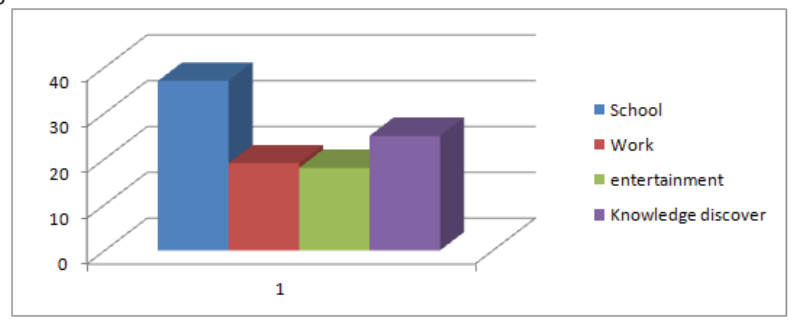

Chart 1. Question 1

Another question made is: Do you want that your job and your tasks must be widely integrated with ICT? We have achieved the following results:

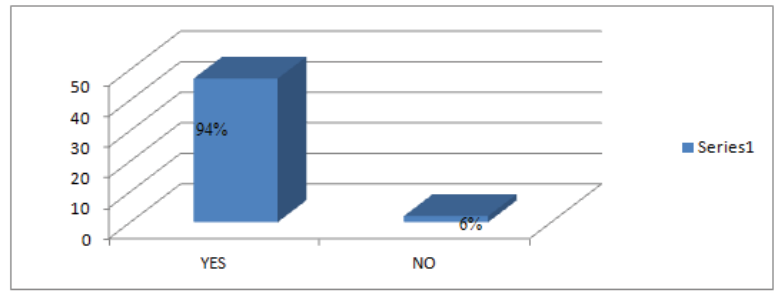

\section{Chart 2. Question 2}

The next question is about the expectations of ICT- education. The question is: What are the expectations if you use the integrated education with ICT education? The alternatives are as follows: $a$. To help children follow their future careers $b$. To increase the social interest of the children c. To increase the knowledge of children d. To improve the ability of students in their communication e. To help children survive in modern society $\mathrm{f}$. To help them better understanding the truth, the good, and the splendid.

The results based on the responsess of the students are:

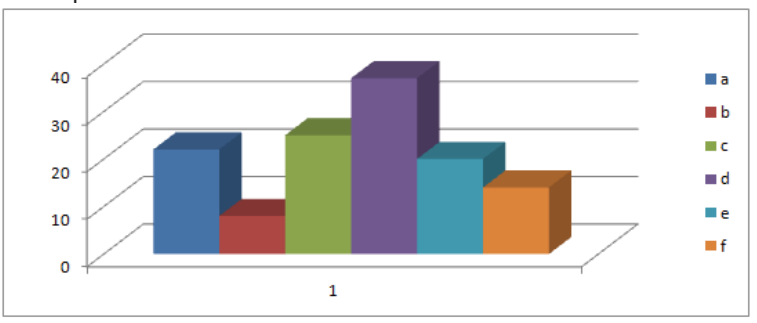

Chart 3. Question 3 
Noticeably we can see the outcome of these two questions, to show that the connection and the desire of students and teachers with ICT, is high. The questionnaire also contains questions about teaching procedures, where according to the answers, it is observed a trend towards new methods, where technology is part of this process. High school teachers have an ongoing collaboration with the students, regarding teaching and learning process. Computers and internet are an integral part of the new tasks and knowledge. All these data that are achieved by questionnaire, will be processed by data mining techniques. These techniques are algorithms with specific tasks, which will help us extract significant results. At this point of the study, we may call it also part of data analysis, so the algorithms involved are:

$\checkmark$ Classification algorithms

$\checkmark$ Regression algorithms

$\checkmark$ Segmentation algorithms

$\checkmark$ Association algorithms

$\checkmark$ Sequence analysis algorithms

Algorithms mostly used in the educational environment are classification algorithms. Classification produces a function that maps a data item into one of several predefined classes, by inputting a training data set and building a model of the class atribute based on the rest of the attributes. In this study we have different types of data, and they are combined in several tables. So we use different training data to reach different results. In Data Mining one of the most common tasks is to build prediction models of the class of an object on the basis of its attributes. Here the object can be seen as a student, lecturer, customer or even a single character. Attributes of such objects can be, for example the student object, pass rate, interactivity, weight and gender, whereas the class of the student object would most commonly be positive/negative for a certain disease.

\section{Concluding Remarks}

This article is part of a study still unfinished, but that gives information about the use of technological tools in Albanian educational system. Albanian educational environment is a developing environment, which has just entered the field of technology. Through the study is created an idea of who is using the tools and technology platforms (by age group), what is the use of (the purpose), trying to find a connection between desire, work, and high performance that we want to achieve. This study examines the implementation of distance learning through an analysis of how the Albanian students are trying to use these technologies \& methods, and with what impact of performance. DM techniques and methods can be used in every aspect of our lives. Now they are being used on the teaching environment. We are able to monitor the performance of each student, teacher, etc., and can extract data, which can be used by DM techniques to achieve certain goals. DM techniques can help to improve the educational system.

Also through this article we want to show: what are the expectations of the Albanian environment, towards technological tools? The questionnaire helps us to understand where the Albanian education system is as well as to reach a final result: Is it time that technological tools should be used in this environment?

\section{References}

Curriculum of Information and communication technology on the teaching process. [Online] Available: http://www.vet.al/files/skelet /2013/TIK-Niveli\%20I-12.pdf

John Sanchez, Mary E. Stuckey, and Richard Morris, Distance Learning In Indian Country: Becoming The Spider On The Web Journal of American Indian Education, Volume 37 Number 3, Winter 1998.

Miriam Bar-Yam, Kathleen Rhoades, Linda Booth Sweeney, Jim Kaput, and Yaneer Bar-Yam, Changes in the Teaching and Learning Process in a Complex Education System. [Online] Available: http://www.necsi.edu/research/management/education /teachandlearn.html

RapidMiner 4.6, User Guide, Operator Reference, Developer Tutorial

Jing Luan, PhD, Chief Planning and Research Officer, Cabrillo College, Founder, Knowledge Discovery LaboratoriesData Mining Applications in Higher education. [Online] Available: http://www.spss.ch/upload/1122641492_Data\%20mining\%20applications \%20in\%20higher\%20education.pdf

Buletini i Shkencave Natyrore (Online), ISSN 2305-882X, Senada Bushati, Ilia Ninka; Data mining dhe sistemi arsimor shqiptar, teknika dhe aplikacione,

XindongWu · Vipin Kumar · J. Ross Quinlan · Joydeep Ghosh · Qiang Yang ·, Hiroshi Motoda · Geoffrey J. McLachlan · Angus Ng · Bing Liu - Philip S. Yu ·, Zhi-Hua Zhou · Michael Steinbach · David J. Hand · Dan Steinberg, Top 10 algorithms in data miting 
